\title{
Library Exhibitions and Visual Literacy
}

\author{
Patti Gibbons \\ University of Chicago, USA \\ Carol Ng-He \\ University of Chicago, USA
}

\begin{abstract}
Library exhibitions showcase collections and can be laboratories where users apply key visual literacy skills, such as making close observations, practicing interpretation, and challenging assumptions. Library exhibitions facilitate self-directed inquiry and have a wide pedagogical range. At academic libraries, faculty include exhibition curation and viewing in their curriculum to promote scholarship and activism. Public libraries use exhibitions to cultivate civic interest and encourage intergenerational and multi-cultural learning. Across settings, exhibition experiences support visual learning, prompt critical thinking, and mobilize change. Through examining contemporary library engagement models such as the American College and Research Library's Visual Literacy Competency Standards for Higher Education, this paper provides examples of exhibits that illustrate ACRL's visual literacy benchmarks. Additionally, the paper provides a brief overview of recommendations for partnering with libraries to expand opportunities for visual learning.
\end{abstract}

Keywords: Association of College and Research Libraries, curation, engagement practices, library exhibitions, visual literacy

\section{Introduction}

Library exhibitions can inspire, illuminate hidden facts, challenge assumptions, build personal connections, and initiate change. At academic libraries, faculty use exhibitions in their curriculum to engage students in exploring diverse subjects and as platforms to promote scholarly dialogues that spur social activism. In public libraries, exhibitions cultivate interest in civic and public issues and encourage intergenerational and cross-cultural learning. In art museum libraries and other special libraries exhibits highlight collection strengths and bring their missions to life. Overall, exhibitions play incredibly active roles in engaging people with library collections across a variety of settings.

Modern library exhibitions more than celebrate and highlight library resources and collections; rather, they serve as workshops where users can practice and gain key cognitive skills. Through exhibits, curators and visitors make close observations, ask questions, share constructive critiques, stimulate creativity, develop divergent thinking, and practice making interpretations. For librarians, exhibitions allow them to expand their role as curators and share their instructional expertise in different ways. It is paramount for librarians to have a deep understanding of the critical information literacy skills underpinning their work in order to increase their exhibitions' pedagogical effectiveness.critical.

This paper explores the role of library exhibitions and exhibit spaces in promoting critical literacies, namely visual literacy as defined and measured by the Association of College and Research Libraries' Visual Literacy Competency Standards for Higher Education. Furthermore, this paper examines skills gained during exhibition curation work and exhibition visits to highlight ways library exhibits help further visual literacy and meet the ACRL's seven standards of visual information literacy. Further, this paper draws upon examples of exhibitions from different libraries to illustrate ways library exhibitions promote visual literacy and encourage people to consider the possibility of using library exhibitions or collaborating with libraries on exhibition projects.

\section{Library Exhibitions, Curation, and Visual Literacy}

Traditionally, libraries are seen as text-driven institutions and not readily considered places for visual experiences or training. However, library collections are filled with maps, posters, photographs, as well as illustrated books. Exhibitions provide libraries an opportunity to display visual examples from their holdings in ways that tell stories, engage visitors, and, in turn, create an environment primed for visual learning and 
teaching.

To create an exhibition, curators assess source materials, select visual examples to illustrate a defined narrative, and write interpretively in a way that directs and instructs viewers to look critically at and analyze materials on display. Curators teach information analysis methods based largely on effective visual communication techniques. Exhibition development work promotes visual literacy by requiring curators to articulate image needs, effectively access search tools to identify image sources, analyze the meaning of visual media within larger historical/interpretive frameworks, assess the reliability and validity of image sources, successfully employ images, use a variety of tools and technologies to create visual media, and follow legal and ethical best practices when using visual media.

In creating exhibits, curators follow the ACRL's Visual Literacy Competency Standards and help libraries promote visual culture and understanding through exhibitions. With knowledge and awareness of visual literacy best practices and competency benchmarks, libraries can play a direct and active role in promoting visual literacy education through their exhibits to "develop the critical thinking and evaluation skills essential to participation in visual culture" (ACRL Board of Directors, 2011). As curators build visual interpretive skills through exhibit work, they become better able to engage exhibit visitors through the content and programming they create.

As educational institutions, libraries use exhibitions to advance their mission. As valuable as the library's collections, exhibitions are a critical service that libraries offer to their communities. Exhibitions are powerful visual communication tools that can promote artistic literacy and facilitate creative development. A library with an exhibition program regularly provides opportunities for visitors to experience the visual world and helps its community develop an understanding and appreciation of art in its diverse forms (see Figure 1).

\section{Figure 1}

Special Collections Research Center's exhibition gallery at the University of Chicago Library, photo by Carol $\mathrm{Ng}-\mathrm{He}$

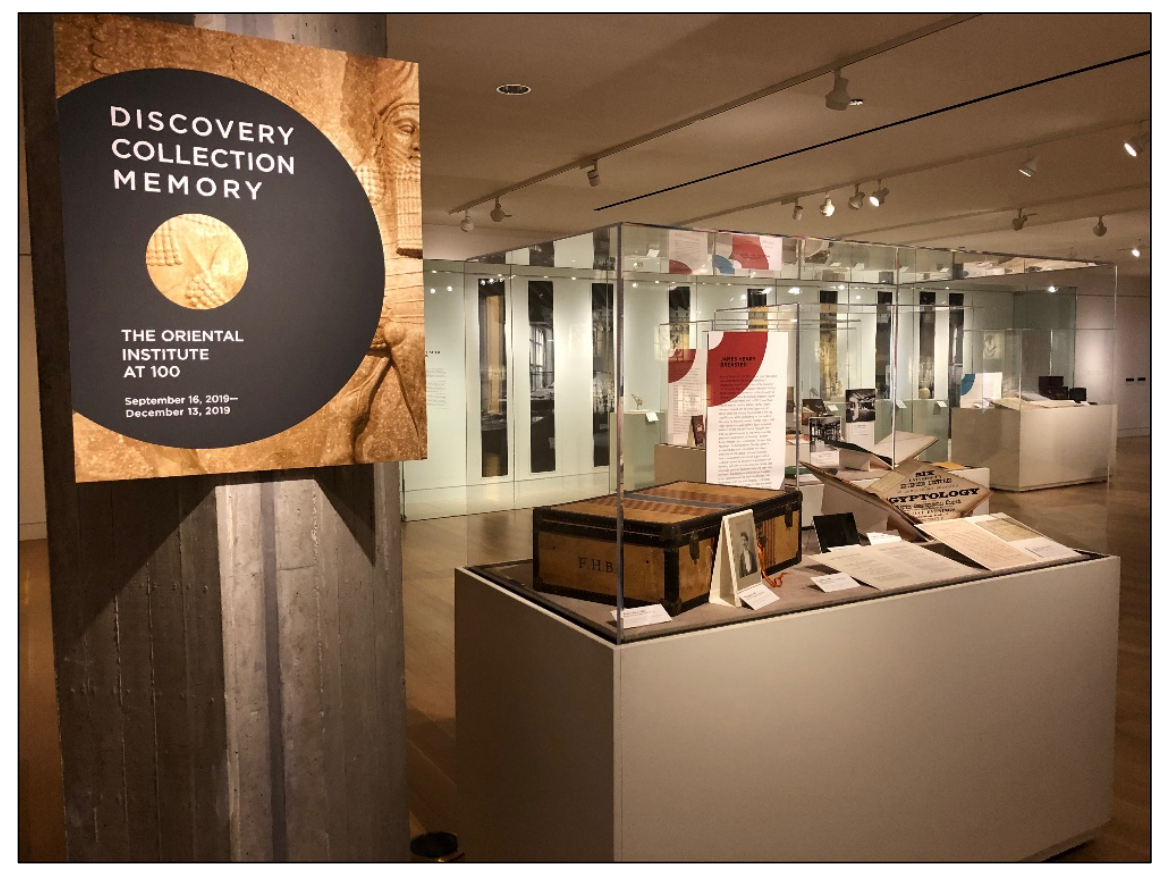

ACRL's Visual Literacy Standards

In 2011, ACRL-the Association of College and Research Libraries, a division of the American Library Association, developed its Visual Literacy Competency Standards for Higher Education as part of a wider 
initiative to map out information literacy standards for higher education and to complement its seminal Information Literacy Standards that guide library instructional initiatives. Visual Literacy Competency Standards address issues presented by visual materials and were developed as curricular tools to promote the effectiveness of visual instruction and learning (ACRL Board of Directors, 2011). When examined in light of exhibition development, the standards highlight particular ways exhibitions help teach visual literacy and demonstrate the visual learning in library exhibition settings.

ACRL defines visual literacy as:

.... a set of abilities that enables an individual to effectively find, interpret, evaluate, use, and create images and visual media. Visual literacy skills equip a learner to understand and analyze the contextual, cultural, ethical, aesthetic, intellectual, and technical components involved in the production and use of visual materials. A visually literate individual is both a critical consumer of visual media and a competent contributor to a body of shared knowledge and culture (ACRL Board of Directors, 2011).

Moreover, the visually literate individual can accomplish seven key standards (ACRL Board of Directors, 2011):

- determine the nature and extent of the visual materials needed

- find and access needed images and visual media effectively and efficiently

- interpret and analyze the meanings of images and visual media

- evaluate images and their sources

- use images and visual media effectively

- design and create meaningful images and visual media

- understand many of the ethical, legal, social, and economic issues surrounding the creation and use of images and visual media, and access and use visual materials ethically

\section{ACRL Standards, Performance Indicators, and Learning Outcomes}

The following are brief synopses of seven library exhibitions. Each illustrates ways library exhibitions map to ACRL's visual literacy standards and notes how the exhibit experience speaks to visual literacy performance indicators and learning outcomes.

\section{Standard 1}

Performance indicator: The visually literate determine the nature and extent of the visual materials needed.

Learning outcomes: The visually literate define and articulate the need for an image, and are able to identify a variety of image sources, materials, and types (ACRL Board of Directors, 2011).

Effective exhibits highlight, rather than overwhelm, in both terms of textual interpretation and visual presentation. Curators take on an editorial role, identifying parts of an exhibit that benefit from visual examples then selecting visual materials that illustrate key concepts, communicate complex data, and best express information.

In 2019, the Special Collections Research Center at the University of Chicago Library partnered with Court Theatre to create an exhibition about developing a play based on Nobel Prize-winning author Saul Bellow's seminal novel The Adventures of Augie March. The curatorial team faced the challenge of turning a textonly book and a modern Word.doc script into a visually compelling exhibit. The team identified ancillary visual materials such as photos, personal artifacts, and manuscript letters from its Bellow archive, and mined Court Theatre's production workspaces for visual inclusions such as a scaled stage model, costume sketches, set renderings, and photographs captured during rehearsals and meetings. Without visual materials to enliven the exhibit's discussion, the show would have remained a flat, word-only story, but the curators identified a variety of image sources and materials and considered a broad range of visual material to enrich the exhibit experience. Here, curators met learning outcomes by articulating image needs and identifying visual sources to best communicate with exhibit viewers. 


\section{Standard 2}

Performance indicator: The visually literate find and access needed images and visual media effectively and efficiently.

Learning outcomes: The visually literate select appropriate sources and retrieval systems for finding and accessing needed images and visual media. They conduct effective image searches, and are able to acquire and organize images and source information (ACRL Board of Directors, 2011).

Serendipitous discoveries are part of any exhibit experiences, including those at libraries. Visitors can find and access images that resonate with them in unexpected ways. In the 2014's More than a Fence: (de)Constructing Mexico/US Borders exhibit at California State University San Marcos (CSUSM) library, exhibit visitors could engage in a multimedia exploration on the symbolic and experienced impact of the Mexico-U.S. border through an interactive installation of photography, sculpture, and texts. Created in collaboration with school professors, students in the Introduction to Sculpture class, and community artists, the exhibit engaged visitors in reflecting on the meanings of the borderlands and immigration. Before designing and constructing their own concepts of the border walls, students participated in an intensive group research project. The border walls students created ranged from "an open window next to a padlocked door; a colorful Día de Los Muertos style skull adorned with flowers; a drone flying overhead, attached to wires above the library gallery" (Chu, 2018). Visitors were invited to participate in the dialogues by responding on a slip of paper. Over the course of the semester, the chain-link fence was woven with hundreds of slips of paper. Visitors cruised the exhibition on their own, informally, searching and accessing images and visual media, which allowed them to ponder and perhaps make sense of the layers of complexity of the issues presented.

\section{Standard 3}

Performance indicator: The visually literate interpret and analyze the meanings of images and visual media.

Learning outcomes: The visually literate can identify information relevant to an image's meaning; situate an image in its cultural, social, and historical contexts; and validate interpretation and analysis of images through discourse with others (ACRL Board of Directors, 2011).

Exhibits not only showcase photographs and other visual materials, but also probe and ask larger questions, tease out an image's significance to larger issues that are interpreted within cultural, social, and historical contexts. Ideally, this interpretive process is interactive and will initiate relevant discussions and discourse with others.

In 2016, the California State University San Marcos Library exhibited (In)Visible Project: Critical Perspectives on Homelessness and Hunger at CSUSM as part of its ongoing Context Library Series in which programming "is designed to encourage the campus community to have conversations about difficult topics, and to mobilize students, staff and faculty to take action" (Fraiser, 2016). In the exhibit (see Figure 2 ), through striking portrait photography and poignant autobiographical narratives, Roberto Baer Guerra's multimedia installation provided a dignified and intimate portrait of San Diego's swelling homeless population. The exhibit and related events aimed to expose and confront the stigma surrounding homelessness, raise awareness about the realities homeless people face, and provide the library's community an opportunity to come together to learn, discuss, and take action to address the tough social issue. This exhibit's success rested largely on its visual expressiveness and prompted to place imagery into a larger social understanding. The exhibit met standard three's performance indicators to situate images within cultural/social contexts and exhibit programs that promoted discourse among visitors.

\section{Standard 4}

Performance indicator: The visually literate evaluate images and their sources.

Learning outcomes: The visually literate evaluate the effectiveness and reliability of images as 
visual communications. The visually literate evaluate the aesthetic and technical characteristics of images. The visually literate evaluate textual information accompanying images. The visually literate make judgments about the reliability and accuracy of image sources (ACRL Board of Directors, 2011).

\section{Figure 2}

(In) Visible Project exhibition at California State University San Marcos Library, photo permission by Melanie Chu

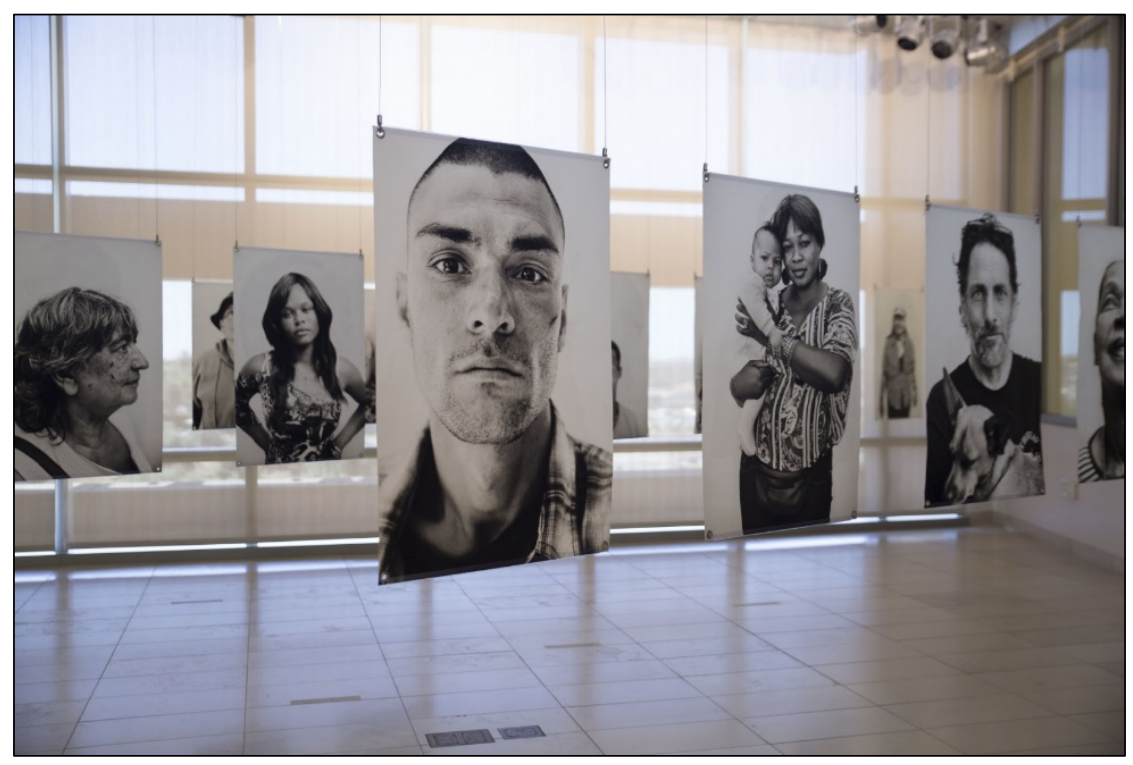

The Naming of Things: Selections from the NYPL Picture Collection was an interactive exhibition at the Grand Central Library on display in 2019. The exhibit was a collaboration between the Pratt Institute and the New York Public Library (NYPL), and the exhibition was first presented at the Pratt Photography Gallery in 2017. Using images from the NYPL Picture Collection, Pratt Institute students enrolled in the Curatorial Practices course curated the exhibition to show visitors the subjective nature of the cataloging process, in which images are categorized for the public to search and access at the library. The student curators engaged visitors and asked them to consider and experience how words could define images and how those words affected a viewer's understanding of images. Visitors used their judgment to catalog images to name a selection of un-cataloged items.

By engaging in the cataloging process, audience members gained a greater appreciation for how images function in our culture, how people define them, and how others react to the definitions ascribed to them. The student curators of The Naming of Things "[inverted] the more conventional relationship between digital technology and pictures: the custom-built application that allows visitors to 'name' the pictures is in the service of the objects that are present in the gallery" (Pratt Institute, 2017).

\section{Standard 5}

Performance indicator: The visually literate use images and visual media effectively.

Learning outcomes: The visually literate use images effectively for different purposes. The visually literate use technology effectively to work with images. The visually literate use problem solving, creativity, and experimentation to incorporate images into scholarly projects (ACRL Board of Directors, 2011).

University of Chicago Library bibliographer and professor in the Center for the Art of East Asia, Dr. Katherine R. Tsiang, authored a comprehensive exhibition catalog for the traveling exhibit Echoes of the Past: The 
Buddhist Cave Temples of Xiangtangshan (Smart Museum, 2010). For the first time in many decades, the exhibition brought together works of sculpture held in isolated collections and pieces that sustained damage when removed from their original context. These sculptures were shown together with digital video installations showing the sculptures in the caves. Visitors had an opportunity through interactive workstations to explore the caves, see 360-degree views of the sculptures, and virtually relocate the sculptures back to the original sites. Technology allowed visitors to examine computerized reconstructed images of damaged sculptures and 3D-printed models of select sculptures accompanied the exhibition.

For the exhibition, curators enlisted the technical expertise needed to scan the sculptures and cave sites, and they used the data to render multi-dimensional images that accompanied smaller sculptures on display. The team reached standard five's learning outcomes, showing that the visually literate are able to use technology effectively to work with images and are able to incorporate images into scholarly projects. Their masterful use of multimedia technologies vastly increased the exhibit's understandability, allowing visitors the opportunity to view reconstructed art in situ and based its visualizations as part of the work of larger scholarly projects studying the art and history of the Xiangtangshan caves.

\section{Standard 6}

Performance indicator: The visually literate design and create meaningful images and visual media.

Learning outcomes: The visually literate produce visual materials for a range of projects and scholarly uses. The visually literate use design strategies and creativity in image and visual media production. The visually literate use a variety of tools and technologies to produce images and visual media. The visually literate evaluate personally created visual products (ACRL Board of Directors, 2011).

Born to Create, an annual art exhibition held in Chicago Public Library's Harold Washington Library Center is a good exemplar showing how exhibits can engage students in producing visual materials for a range of projects and teach them to apply design strategies and creativity in visual media production.

Born to Create showcases eclectic collections of original art created by Chicago high school teens that submit work to Chicago Public Library's annual Teen Winter Challenge. Since 2015, the Teen Winter Challenge has provided a platform for teens to express themselves creatively and submit work for review. In 2018, in honor of the City of Chicago's Department of Cultural Affairs and Special Events' Year of Creative Youth programming theme, Born to Create brought together eighteen artists and thirty-three works of painting, photography, video art, fashion design, and musical composition. In conjunction with that year's exhibition, the library also hosted an opening reception in the library's exhibit gallery that featured a moderated panel discussion with selected winners.

Born to Create illustrates a community participatory exhibition program where a library partners with youth and a school district's visual arts department to effectively cultivate students' proficiency in using tools and technologies to produce visual media that amplify personal stories and reflections (see Figure 3).

\section{Standard 7}

Performance indicator: The visually literate understand many of the ethical, legal, social, and economic issues surrounding the creation and use of images and visual media, and access and use visual materials ethically.

Learning outcomes: The visually literate follow ethical and legal best practices and properly cite images and visual media (ACRL Board of Directors, 2011).

Exhibits provide an opportunity to teach about fair use, copyright, and intellectual property as it applies to image content. In physical exhibits, labels accompanying images and items on display include attributions and credit statements that identify information about the creator, date/place of publication or creation, as well as ownership notes and disclaimers about image permissions. The University of Chicago Library's online exhibit En Guerre: French Illustrators and World War I includes images with active rights (2014). In 
the virtual exhibit, captions for protected images include notes identifying the image rights owner. The library holds a renewable fee-based contact with the Artist Rights Society to include this image, with royalties supporting the artist's estate. Furthermore, on the exhibit's rights and reproduction page, the library includes additional notes summarizing fair use of the library's materials, the artist's image rights, and instructions for those seeking copyright permissions (2014). This example demonstrates how the visually literate properly cite images and ethically commit to paying royalty fees.

\section{Figure 3}

Born to Create exhibition at the Chicago Public Library, photo by Carol $\mathrm{Ng}-\mathrm{He}$

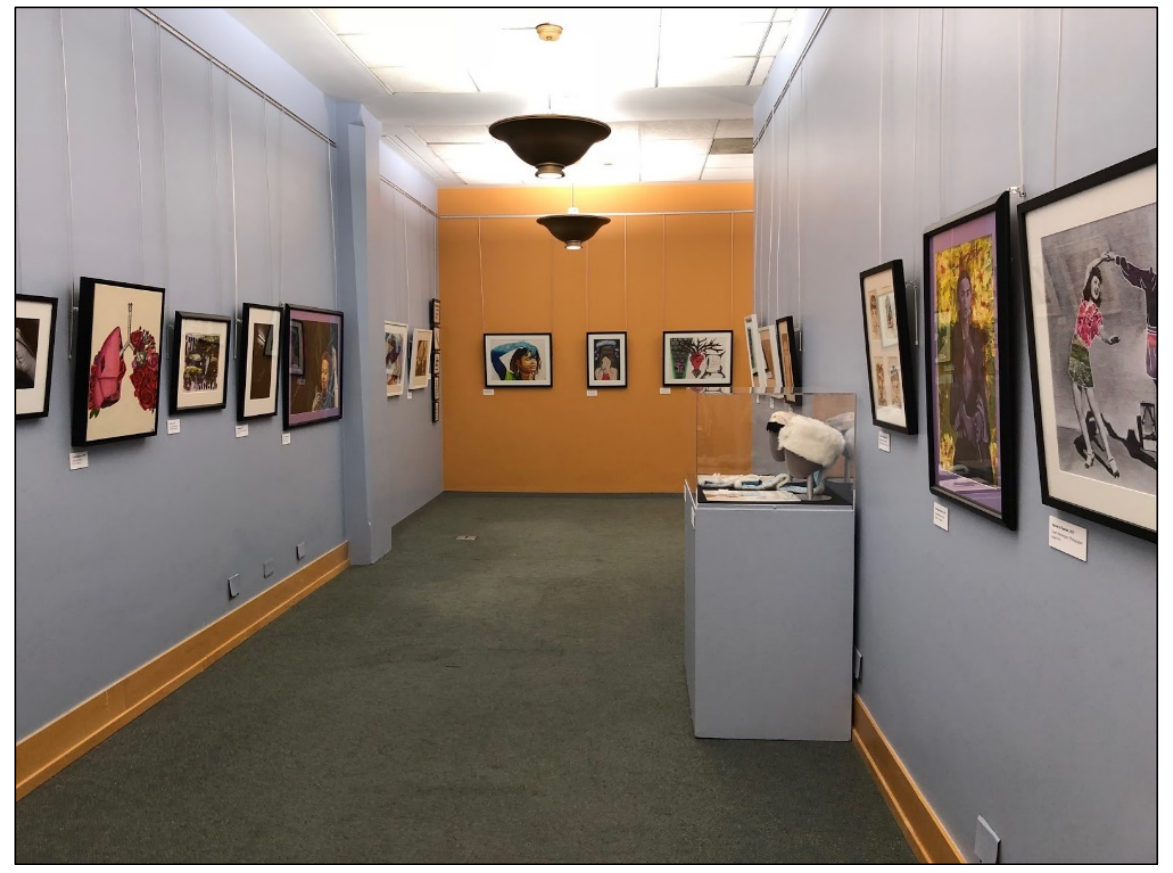

Exhibitions such as the seven aforementioned examples illustrate the potential displays have to be part of visual literacy educational experiences for both the curatorial team and visitors. Examining exhibition work within the framework of the ACRL's standards helps breakdown the exhibition development process and visiting experience to isolate and identify particular visual literacy teaching opportunities present in the exhibition experience, which help librarians more successfully teach (or further develop their own) exhibition development skills, while also promoting exhibition viewing experiences that develop visitors' visual literacy skills. Librarians who understand their work within the context of the ACRL's standards are primed to better educate and promote visual literacy through their exhibit work.

\section{Collaboration and Partnership Opportunities}

Librarians aim to create quality and meaningful exhibition experiences that resonate with library visitors. Collaborating with others outside their organization helps inform their work, direct their efforts, and amplify the effectiveness of their exhibit programs. Forming and growing community partnerships help librarians, and key constituents understand each other better and extend the reach of services and programs. The following recommendations are ways libraries and key partners can work together and improve exhibition effectiveness, supporting teaching and learning critical literacy skills such as visual literacy.

\section{Parents and Caregivers}

Exhibitions in public libraries offer an excellent entry point for intergenerational interactions, and libraries, on the whole, are shifting from being purely a repository of books to a dynamic hub for learning and connection ( $\mathrm{Ng}-\mathrm{He} \&$ Gibbons, 2021). Increasingly, public libraries are offering enriching exhibit 
experiences and providing space for families and individuals to create cherished memories and to build strong community bonds. Librarians continually explore ways to serve visitors' needs. Parents and caregivers can voice their family's interests, curiosities, and opinions to help librarians identify exciting topics and areas of interest that they may develop into exhibits.

\section{Teachers}

Teachers can energize their curriculum by partnering with libraries and exploring library resources, including exhibitions. Educators can incorporate both physical and virtual exhibitions into their curriculum and lesson plans in fun ways that align with their learning goals. For example, teachers can arrange class visits to library exhibits or assign self-guided exhibit tours to their students. In advance of exhibition viewings, teachers can prepare pre-visit lessons and onsite activities. Incorporating visual literacy skill-building lessons into these activities can be very effective learning opportunities.

\section{Artists}

Librarians enjoy sharing creative work with their communities and welcome opportunities to display art, and many libraries are open to displaying the work of local artists. Most public libraries have cases and display spaces in their facilities that are available to showcase artwork. Artists can also partner with librarians to organize hands-on art workshops or demonstration programs at the library. Local artists may consider forming artist meet-up groups at the library to establish relationships with the library's staff. These partnerships may feed future exhibitions and related public engagement activities. Thinking outside of the traditional gallery space, artists can partner with libraries to create programming that reaches a local audience and gives libraries access to visual arts not typically found in their collections.

\section{Fellow Librarians}

Librarians can collaborate on inter-institutional exhibits with colleagues at other libraries to tap into a wider range of library collection materials and staff expertise while broadening and growing audiences. Forming an exhibition consortium pools resources and helps librarians develop professional networks to support their exhibition activities. Working together leverages staff talents and collection materials needed to produce library exhibitions while also helping librarians stretch budgets and amplify community engagement opportunities.

\section{Museum Colleagues}

Libraries may be terrific venues to host traveling museum exhibitions. Some libraries lack the staff expertise, scope of collections, physical spaces, and security needed to produce and host exhibitions typical in quality to those produced by galleries and museums, and hosting a traveling show (or a scaled-down version), allows libraries to offer a high-quality, sophisticated exhibit experience. Additionally, library exhibit visitors differ from traditional gallery and museum visitors, insomuch as most visit a library for information and access to library materials, and many discover exhibitions during their visit rather than it being an experience that initiates their outing. Marketing and promoting traveling exhibits can help drive traffic to the library. The name power of the museum could help increase traffic to the library while also promoting the museum to library visitors. Through collaboration, both organizations promote each other's services.

Overall, exhibitions provide opportunities for partnerships that broaden a library's reach to its constituencies and help the library more clearly understand the needs and interests of its key stakeholders. Through collaboration, libraries can strengthen symbiotic ties with essential groups of library users and better position exhibitions for success, thereby increasing their potential to educate and promote critical literacy skills such as visual literacy. Librarians who understand their work within the needs of collaborative networks are better able to increase the impact of their work and help their exhibitions promote visual literacy skills and learning.

\section{Summary}

Increasingly, as exhibition creation and development processes become more diverse and sophisticated in subjects and deliveries, libraries are creating exhibits that better engage and educate their audiences. Curators who consider the ACRL's Visual Literacy Competency Standards while creating exhibits are able to identify visual literacy teaching opportunities present in the exhibition experience, both for themselves as content creators and for those visiting the exhibit. Curators who improve their visual literacy skills are better 
positioned to create experiences for visitors that help develop and build analytical and visual skills. Furthermore, libraries broaden the reach of their exhibition programs by forming collaborative partnerships with exhibition constituents. Collaboration, in turn, helps libraries increase their ability to educate and impart visual literacy skills through their unique exhibit experiences. Overall, exhibitions across all types of libraries play a role in inspiring and educating visitors while also teaching skills to help people effectively employ, evaluate, and consume visual media.

\section{References}

ACRL Board of Directors. (2011). ACRL visual literacy competency standards for high education. http://www.ala.org/acrl/standards/visualliteracy

Chu, M. (2018, May 2). Out of context: understanding student learning through museum studies. In the Library with the Lead Pipe. http://www.inthelibrarywiththeleadpipe.org/2018/out-of-context/

Frasier, W. (2016, October 19). (In)Visible project confronts stigma surrounding homelessness. CSUSM News Center. https://news.csusm.edu/invisible-project-exhibit-confronts-stigma-surroundinghomelessness/

Ng-He, C. \& Gibbons, P. (2021). Exhibits and Displays: A Practical Guide for Librarians. Lanham, MD: Rowman \& Littlefield.

Pratt Institute. (2017, October 31). Pratt students curate interactive exhibition from New York Public Library Picture Collection. https://www.pratt.edu/news/view/pratt-students-curate-interactiveexhibition-from-new-york-public-library-p

Smart Museum. (2010). Echoes of the past: the Buddhist cave temples of Xiangtangshan. https://smartmuseum.uchicago.edu/exhibitions/echoes-of-the-past/

University of Chicago Library, Special Collections Research Center. (2014). En guerre: French illustrators and World War I. https://www.lib.uchicago.edu/collex/exhibits/en-guerre-french-illustrators-andworld-war-i/allies/

APA citation format $\left(7^{\text {th }}\right.$ edition) for this publication:

Gibbons, P., \& Ng-He. C. (2021). Library Exhibitions and Visual Literacy. In J. Lee, S. M.

Christensen, S. Beene, X. Chen, and W. Huang (Eds.), Visual literacy in the virtual realm: The

book of selected readings 2021 (pp. 30-38). International Visual Literacy Association.

https://doi.org/10.52917/ivlatbsr.2021.014 